Postgrad. MED. J., (1966), 42, 120

\title{
JOURNAL CLUBS
}

\author{
D. MatTingly, M.B., M.R.C.P. \\ Director, the Postgraduate Medical Institute, \\ University of Exeter.
}

I THINK that I should make it quite clear from the start that my experience of journal clubs is very limited, and I am sure that there are many here today who could speak with more authority on this subject. I was never invited to join a journal club during the first ten years of my post-graduate training, and it is only in the past two years that I have become aware of their existence. I suspect that mine is not an isolated experience and that the idea of journal clubs has not caught on in this country as it has in the United States, where they are a regular and often compulsory feature of hospital life. There have been frequent references to journal clubs in the torrent of articles on postgraduate education which have poured out over the past ten years, but I have been unable to find any article which deals with this subject in any detail. I think that the first question therefore that we have to ask ourselves today is what do we understand by the term "journal club" and what do we expect to get out of them, and we shall probably find that we all have quite differing views on the subject.

I would define a journal club as a group of doctors meeting regularly to discuss papers of interest in the current medical journals. I realise that this definition may not be completely acceptable to everyone, but at least it provides a basis for discussion. It is difficult to be more precise than this for the specific purpose and organisation of each journal club will depend on the experience and interests of its members. For junior hospital staff it may be their first introduction to the systematic use of the medical journals, whilst their more senior colleagues may find it a convenient way to share the task of surveying the current literature in a particular specialty. In the latter case one would expect a more critical evaluation of the published data.

The essential feature of any journal club, however, is that all the members should present papers at one time or another and take part in the subsequent discussions. In this respect journal clubs differ from most other forms of postgraduate education in that the audience is definitely not a passive one, and there is ample opportunity for a two-way traffic in ideas. For $\overrightarrow{0}$ this to be effective there must be some limitation to the size of the club and the maximum number is probably around a dozen members, althougho some of my colleagues feel that this is too many and that the optimum membership is about six. to eight.

\section{Membership}

Most journal clubs are organised on a depart $-\vec{N}$ mental basis but I believe that there is a placeo for interdepartmental journal clubs, particularly_ for the junior hospital staff in the smaller hos-T pitals. Large and Wells (1965) organised an in $-\frac{D}{\square}$ terdepartmental journal club for the junior hospital staff at the Royal Berkshire Hospital bute eventually abandoned it in favour of depag $-\overrightarrow{0}$ mental clubs. Each of the area senior registrafsos in turn took the chair, and five or six peofies reviewed articles which had been of interest too them. In retrospect there seem to be have beens two main reasons for the failure of this particu-o lar journal club. Firstly, poor organisation en-응 gendered by a rotating system of chairmanship, which prevented anyone gaining sufficient ex-⿳亠丷厂二 perience to do the job well; and secondly,, because it was impossible to cover the whole field of medicine and surgery adequately.

Clubs of this sort may be more successful in? other areas. At Exeter, for example, the junior hospital staff have been running an interdepart- 3 mental journal club for over a year now, under the regular chairmanship of the senior medical registrar. Membership is restricted to the registrars and senior house officers in all the special-s ties and the average attendance is about nine $\rightarrow$ At first they met once a month between 5.30 . p.m. and 7.30 p.m. but they now meet every Thursday evening at the same time. Possibly the fact that they meet in the R.M.O's room over a glass of beer has something to do with $\omega$ its continuing popularity. Each member choosese two or three journals to read and selects those papers in his own specialty which he thinks will be of general interest. Only three or four papers are discussed at each meeting in order to ensure ${ }^{0}$ an adequate discussion. 
There is no doubt that having a permanent chairman to organise the meetings has a lot to do with the continuing success of this particular club. Pre-registration housemen are not invited to join, mainly because of the numbers involved, but in smaller hospitals there is no reason why all the house staff should not participate in an interdepartmental club of this sort. Too much should not, however, be expected of the preregistration housemen. They may well need considerable help from the registrars, both in the selection of papers and in their evaluation.

\section{Departmental Clubs}

It seems to be generally accepted that the most successful journal clubs are those which are run on a departmental basis, and I should like to spend the next few minutes discussing some of the factors which can make or mar a club of this sort. Most of the journal clubs in the United States appear to be run on a departmental basis, and I was interested to hear recently of the experiences of a young woman doctor who has just spent two years as a resident in a paediatric department in Cleveland. During her first year the whole paediatric department used to meet once a fortnight between 7 and 9 p.m. at the chief's house over a bottle of wine. All the residents were allocated two journals by the head of the department and were expected to present papers in turn. During her second year the journal club still met once a fortnight but the time and venue was changed. It was now held at the hospital and started at 6.45 a.m. and went on to about 8 a.m. Breakfast was apparently eaten during the course of the proceedings and attendance was compulsory. I think that there must be some fundamental difference between the circadian rhythm in the United States and this country, and I cannot see any future for journal clubs at this time of day here.

It is very difficult to find a time and day which suits everybody, but I think that it is very important that a journal club should always meet on the same day and at the same time in order to establish a habit amongst its members. At Exeter, the Physicians' journal club meets once a month on a Wednesday evening between 6 and 7 p.m. Membership of this club is limited to the five general physicians and the two medical registrars, but house physicians are in- vited from time to time to present papers and to join in the discussions. Each member chooses two or three journals and selects those papers which he thinks will be of interest to his colleagues. Two members undertake to make contributions at each meeting and each contribution may consist of a single paper or of a number of papers on the same subject, not necessarily from the same journal.

A fatal mistake is to try and cram too much into a meeting, thus limiting the discussion which is the most valuable feature of this form of education. When we first started one of my colleagues was extremely enthusiastic and said that it was the most efficient, economical, and effective method for the practising physician to keep abreast of his subject, and proposed that we meet once a week. In principle I am sure that he is right and that we should meet more often, but in practice I have noticed that he finds it just as difficult as the rest of us to meet regularly once a month.

I have no experience of trying to run a journal club for general practitioners but I understand that others who have attempted this have had little success (Paulley, 1963). Surely the impetus for this sort of activity must come from the general practitioners themselves, but if they want to start journal clubs it is very important that there should be a well-stocked journal library in the postgraduate medical centre in their vicinity.

\section{Conclusion}

I think that most of us would agree with Garland (1964) that regardless of all other forms of communication, the printed word appears to remain, at least for the present, the basic agent for the distribution and repositing of knowledge. This knowledge, certainly as it applies to medicine, is tending to flow in narrower and deeper channels. It seems to me that journal clubs are one way in which we can help each other to navigate these difficult waters.

\section{REFERENCES}

Garland, J. (1964): A Proper Study of Mankind. New Engl. J. Med. 270, 1137.

LARGE, J. M. and Wells, R. S. (1965): Junior Staff and Postgraduate Education, Postgrad. med. J. 41. 117.

Paulley, J. W. (1963): Continuing Education in an Area Hospital. Postgrad. med. J. 39, 321. 
Dr. Ferriman: Would it be wrong to say that each member should take 2 or 3 journals and tell his colleagues which papers in them are worth their attention?

Dr. Mattingly: No, I am sure that this is one funotion of a Journal Club. But it is equally important to take 1 or 2 papers and discuss them oritically.

Dr. C. T. ANDREws : At Truro we have had a Journal Club for General and Chest Physicians for two or three years. We invite to this our Medioal Registrars and any other member of the junior staff who may be working for the M.R.C.P. diploma. We do not ask the Chest Physicians to review chest journals as we think there is a danger that they will involve us in a discussion of the minutiae of pulmonary function. Our monthly meetings last two hours and there is an average attendance of about 12. Anyone not attending regularly is taken off the mailing list. This arrangement has worked very successfully.

DR. W. J. STOKES: Although there is obviously a place for specialised and depantmental Journal Clubs, at Stoke Mandeville Hospital the Journal Club includes staff at all levels and meets every Monday at 1.20 p.m. in the Nuffield Library. Coffee is served. Under a permanent and erudite chairman, four speakers come prepared to present a special article or two from their allotted journal for periods up to ten minutes, allowing time for discussion. Numbers attending average ten to twelve, although perhaps twenty belong.

We feel that junior staff should realise how little of the current literature anyone of us is capable of reading, and should be encouraged to present their contribution, perhaps under the guidance of a chief or registrar.

The Journal Club would seem a valuable part of hospital routine; and although attendance cannot be made compulsory, we have recently appealed that some pressure be made through consultants that their respective firms attend whenever possible.

Those who complain concerning the contents of the library or of the postgraduate programmes only have themselves to blame! They are well represented on the Postgraduate Advisory Committee, are repeatedly asked for suggestions by the Tutor, and should complete the questionnaires which they receive through the post.

DR. Rinsler (St. Stephen's): The maximum beneffif from Journal Clubs accrues to the person presenting such a paper. I find the ones I present are alway. clear in my memory as opposed to those I listeff to presented by others, because one is very carefu to anticipate criticism. Housemen derive most beneff from the critical evaluation of a paper, which theos are quite unused to doing themselves. Experienced people should guide them.

Dr. Mattingly: There is a place for a club wheret you have everyone. I do not think that we should expect our pre-registration people to spend too muct time reading journals at this stage. I found textbook more helpful in this period myself. Is the exercise. primarily an educational experience for junior stafs or is it education for oneself?

DR. LEATHER (Plymouth): I have been involved i ip Journal Clubs for 10 years and find them very valuable. We get six or eight junior members attendw ing weekly meetings, in University terms, from 9-1థ a.m. on Mondays. Attendance is less good in the evening.

Mr. T. L. Schofield (Bath): I have also had $1 \bar{g}$ years experience. We have departmental clubsconsultant and registrars-but invite S.H.O.s, wh $\vec{\theta}$ are taking higher exams. The meetings are mire successful in the atmosphere of a consultant's home. We regard this as training for junior staff. Jourfis are allocated, especially the important ones, to peow 1 s takling exams. A discussion often develops that binsts far into the night-for instance, one that centred $\bar{D}$ the last leader in the Lancet on gastro-duodena haemorrhage.

DR. PAulley: I very much agree with the lasi speaker about involving the junior staff, but pres registration housemen must not be excluded-this may be their first chance of learning to use the library. They must be helped to evaluate materiat for themselves. We have weekly meetings, discuss sing only one paper-the discussion is the mos valuable part. My experience is that pre-registration. men find this most valuable and their contributions are often the most stimulating. We have made it a parade and the head of the department must be there ibperson.

\title{
INTERDEPARTMENTAL TEACHING
}

\author{
Bernard Lennox, M.D., Ph.D., F.R.C.P.(G), F.C.Path., M.R.C.P. \\ Reader in Pathology, Western Infirmary, University of Glasgow.
}

I HAVE been given twice as long as my fellowspeakers and I have assumed that this is an invitation to try and tackle my subject in some depth. I am going therefore to say very little about such matters as the minutiae of management of clinico-pathological conferences. It is not that they do not matter: they do, but they vary greatly with local circumstances, and or N $^{2}$ the whole it is best to work out the details op the spot. I shall come back to a few practicas points at the end, but I want to spend most op my time dealing with the background, with the ambient circumstances which make good interdepartmental teaching possible. I am welf 